\title{
Research on Liquefied Natural Gas(LNG) inland river transportation security risk assessment and security technology based on risk
} management

\author{
Hu Yuchang ${ }^{1, a}$ and Xu Liansheng ${ }^{1}$ \\ ${ }^{1}$ China Waterborne Transport Research Institute, Beijing, China
}

\begin{abstract}
Using the Analytic Hierarchy Process and taking a certain section of the lower reaches of the Yangtze River as an example, this paper analyzed and identified the risk of inland river transportation of LNG, established the risk assessment criteria. According to the assessment results, it can be concluded that the current security risk situation of inland river LNG transportation is between "general" and "higher", and puts forward corresponding suggestions to improve security.
\end{abstract}

\section{Introduction}

In recent years, with the accelerated implementation of China's new strategy for supporting the Yangtze River's economic belt and the coordinated development of Beijing, Tianjin and Hebei, China has increased the spatial layout of Reform and Opening-up and accelerated the coordinated development of regional economy. As the coordinated development zone of China's East-West interaction and cooperation and the pioneer demonstration zone of ecological civilization construction, the new support belt of the Yangtze River economy, led by ecological priority and green development, is an inland river economic belt with global influence. General Secretary Xi Jinping pointed out that the development of the Yangtze River Economic Zone is a major strategy related to the overall development of the country and is of great significance to the realization of the goal of "two hundred years" and the realization of the Chinese dream of the great rejuvenation of the Chinese nation.

\footnotetext{
a Corresponding author: hycray@163.com
}

The Yangtze River covers nine provinces and two cities, with the population and total economic volume exceeding $40 \%$ of the whole country. In recent years, with the rapid economic development, the demand for energy is also growing rapidly. Under the high pressure of ecological priority, green development requirements and environmental protection, the demand for LNG and other clean energy in the central and Western regions of China is growing rapidly. LNG is a clean energy source. It is of great significance to optimize the energy structure, improve the ecological environment and achieve sustainable development by using LNG.

Inland waterway operation is a sustainable mode of transportation and an important part of China's modern comprehensive transport system, accounting for nearly $40 \%$ of China's water transport. It is a convenient way to transport LNG from coastal receiving stations to demand terminals in central and western regions by inland waterway transportation. Because of its high risk of fire and explosion, the domestic understanding of its inland waterway transport safety is insufficient, and the lack of 
relevant safety management standards for LNG from inland waterway transport, the current standard of inland waterway transport LNG also has many conditions, which restricts the development of LNG inland waterway transport and affects the promotion and application of LNG clean energy.

Previously, for the safety risk assessment of LNG transportation, domestic research mostly focused on navigation conditions, LNG ship operation and risk identification. Gan Haoliang [1] considered that the safety zone of LNG ships in actual navigation should vary according to the characteristics of LNG ships, the conditions of port waters and the changes of traffic flow density. The safety zone of LNG ships should be divided into delimited safety zone and variable safety zone. Wen Yuanqiao et al. [2] proposed a quantitative method to calculate the width of LNG vessel's berthing safety zone. The results show that the width of LNG vessel's berthing safety zone is closely related to the size of LNG vessel, the size of vessel in adjacent waters and the speed of navigation. Wang Chaomin [3] quantitative studied the Adaptability of LNG Inbound and Outbound Channels Using Fuzzy Comprehensive Evaluation Model of Aggregation Method. Guo Weizhi [4] uses ship maneuvering simulator to obtain track distribution records of large LNG ships, and designs a saving channel width algorithm for large LNG ships. The evaluation results show that the scheme not only meets the safety requirements, but also saves engineering funds. $\mathrm{Hu}$ Huiguo et al. [5] constructed an optimization method of LNG ship entry and exit organization scheme based on lattice order decision theory. Zhang Xiaodong et al. [6] proposed a queuing model considering non-simultaneous and simultaneous interference types to simulate the passage status of waterway vessels and effectively evaluate the safety and efficiency of LNG ships entering and leaving the port. Li Hongliang et al. [7] calculated the influence of LNG ships on the main channel capacity of Gaolan Port by using the navigation impact rate model and the channel occupancy rate model respectively. Wang Hairong et al. [8] used the method of fuzzy analytic hierarchy process to determine the weight vector and the fuzzy evaluation matrix, calculated the decision vector, and realized the quantitative risk identification of LNG receiving station. Wang Qingfeng et al. [9] quantitative calculated and analyzed of typical leakage and diffusion of inland river thin film LNG carrier and the consequences of fire and explosion accidents by using PHAST risk analysis software, considering the actual situation of inland river waters in China. Dou Xu et al [10] carried out numerical study on structural damage caused by collision of small LNG ships during inland navigation. Wang Kan et al. [11] proposed an optimization fireball model by introducing the atmospheric transmission rate $\tau$ into the original TNO dynamic model.

MOLEN et al.[12] verified the correctness of TERMISM model in 6-DOF model by measuring actual Mooring Loads of LNG ships under different conditions. At the same time, calculate and analyze the swaying motion and mooring force of ships under surge action. HIGHTOWER et al. [13] analyzed the risk of LNG overflow and diffusion caused by ship accidental damage and intentional damage. The results show that within the range of $500 \mathrm{~m}$ overflow, it will have a greater impact on the safety of personnel and public property, but little impact when it is larger than $1600 \mathrm{~m}$. JOBNSON et al. [14] used the LNG leakage consequence analysis model proposed by the Federal Energy Regulatory Commission to calculate the dangerous area by estimating the leakage rate, diffusion rate, evaporation rate in open water and thermal radiation. HISSONG et al. [15] pointed out that the leak of LNG in water is more complicated than that of storage tanks on land. The key is to estimate the size of liquid pools. They used the method of fuel and energy balance in establishing evaporation and LNG liquid pool models, taking into account multiple LNG characteristic parameters and their changes, as well as the influence of mixing with water. It makes the model more real and effective. KIM et al. [16] analyzed the potential hazards causing the leakage of thin film LNG vessels at the LNG receiving station in Pingze Port, Korea, and quantitatively evaluated the overall leakage accident rate using fault tree analysis method. ELSAYED [17] used Mamdani and Sueno fuzzy reasoning methods to evaluate the risk of LNG ship during loading and unloading. BUBBICO et al. [18] preliminarily assessed the risk of LNG vessel receiving terminal in Panigaglia, Italy. The results show that LNG spillover caused by accident can be basically eliminated, and intentional damage will lead to a large number of LNG leaks causing pool fires, but the impact 
on the residential population can be neglected. NWAOHA et al. [19] used risk matrix method to identify the main hazards in LNG ship maneuvering process, in which the transmission arm LNG overflow and control system failure have the highest hazard level. Further, through fault tree analysis of its causes and fault logic, the method of fuzzy logic reasoning was used to determine its safety level. Kim [20] analyzed the failure behavior of LNG sealed cargo hold under impact.

\section{LNG transportation risk analysis and identification}

\subsection{Risk analysis of LNG ships}

Chinese "Statistical Measures for Marine Traffic Accidents" will be included in the statistics of water traffic accidents into collision accidents, grounding accidents, reef-striking accidents, damage accidents, wave damage accidents, fire and explosion accidents, wind accidents, self-sinking accidents and other water traffic accidents causing casualties, direct economic losses and so on.

Inland river waters are characterized by complex channel conditions, small channel width, more shoals, more bends, dramatic changes in water flow, more bridges, and high traffic density. There are a large number of ships on inland waterways, with dense wharf layout and frequent operation of ships entering and leaving the wharf, which results in the risk of ship traffic accidents. The risk of inland waterway transportation of LNG ships depends on many factors, among which the most important are: ship type, physical and chemical characteristics of dangerous substances, characteristics of waterway, etc. Natural factors such as wind, cyclone and fog are also important factors causing ship collision, self-sinking, grounding and other traffic accidents. At the same time, LNG is a flammable and explosive dangerous cargo, which has occurred. Accident risks such as fire and explosion of live ships.

Therefore, the main types of accidents that may occur in inland LNG ship transportation are grounding, collision between ship and ship, collision between ship and wharf or bridge, self-sinking of ship, fire and explosion of ship, etc.

\subsection{Risk identification of LNG ships}

Explosion or leakage is common in LNG waterway transportation. Explosion or leakage has a great destructive effect, and accompanied by air and water pollution, it brings great economic losses to society. For the risk factors of goods in LNG transportation, the hazards of goods and the possible environmental hazards caused by accidents should be considered.

The factors affecting the navigation environment of inland LNG vessels can be roughly divided into four aspects: natural environmental factors, channel factors, traffic factors and management factors. These factors interact with each other and are complex and changeable. Therefore, it is necessary to accurately grasp the changing law of each factor, accurately and timely locate the position and draw up the correct route in order to ensure the safety of ship navigation system. When analyzing the navigation environment of inland LNG ships, the following aspects should be considered. Channel characteristics include channel curvature, channel intersection angle scale, channel obstruction, etc. Meteorological and hydrological characteristics including wind, current, visibility, etc. Navigation aids including natural and manual navigation aids. Ship trends in waterways include ship types, sailing time, dynamic characteristics, rules of motion, etc. Meteorological characteristics include the characteristics of meteorological changes in navigational waters and their impacts on navigation, etc.

In the actual evaluation, the number of evaluation factors and the accuracy of evaluation are not directly related, so we should pay attention to the role of evaluation factors in the evaluation. The basic principle of determining evaluation factors is to reasonably compose evaluation factor set with as few main factors as possible.

\section{Establishment of risk assessment indicators for LNG transport accidents}

\subsection{Establishment of evaluation index system}

After investigation and statistics, the evaluation factors of navigation environment of inland LNG ships are divided hierarchically, and the indexes affecting navigation safety 
risk assessment of inland LNG ships are determined as follows: wind, visibility, flow, channel width, channel curvature, channel intersection angle, obstacles, traffic flow, special operations, traffic management and navigation assistance. Set the first level of evaluation, evaluation set $\mathbf{U}=\left\{\boldsymbol{\mu}_{1}, \quad \boldsymbol{\mu}_{2}, \boldsymbol{\mu}_{3}, \ldots, \boldsymbol{\mu}_{\mathrm{m}}\right\}$, to construct the first level risk factors set, $\mathbf{U}=\left\{\right.$ hydrological conditions $\boldsymbol{\mu}_{1}$, channel $\boldsymbol{\mu}_{2}$, traffic $\boldsymbol{\mu}_{3}$, management $\left.\boldsymbol{\mu}_{4}\right\}$. Similarly, the second level risk factors set $\boldsymbol{\mu}_{1}=$ \{flow, visibility, wind $\}$, $\boldsymbol{\mu}_{2}=$ \{channel width, channel curvature, channel crossing angle, obstacles $\}, \quad \boldsymbol{\mu}_{3}=$ traffic volumes, special operations $\}, \boldsymbol{\mu}_{4}=\{$ traffic service, aids of navigation $\}$.

In the analysis of related factors, the evaluation criteria are divided into five levels according to the attributes of the target layer. The order from low to high is low, lower, general, higher and high. On the basis of determining the index system of inland LNG ship transportation safety risk assessment, here takes a certain section of the lower reaches of the Yangtze River as an example to determine the safety evaluation criteria by field analysis and consultation with relevant experts. The following evaluation criteria are obtained, as shown in Table 1.

Table 1. Risk classification standard of navigation safety assessment indicators for LNG ships

\begin{tabular}{|c|c|c|c|c|c|}
\hline Risk & Low & Lower & General & Higher & High \\
\hline $\begin{array}{c}\text { Days of poor visibility } \\
\text { (days/years) }\end{array}$ & $0-15$ & $15-20$ & $20-30$ & $30-40$ & $>40$ \\
\hline Wind speed (m/s) & $0-5$ & $5-10$ & $10-15$ & $15-25$ & $>25$ \\
\hline Velocity of flow (m/s) & $0-0.4$ & $0.4-1.2$ & $1.2-2.2$ & $2.2-3.2$ & $>3.2$ \\
\hline Width (m) & $0-0.3$ & $0.3-0.5$ & $0.5-0.8$ & $0.8-1.0$ & $>1.0$ \\
\hline $\begin{array}{c}\text { Maximum turning } \\
\text { angle (degree) }\end{array}$ & $<15$ & $15-30$ & $30-45$ & $45-60$ & $>60$ \\
\hline $\begin{array}{c}\text { Crossing angle } \\
\text { (degree) }\end{array}$ & $<20$ & $20-45$ & $45-60$ & $60-70$ & $>70$ \\
\hline $\begin{array}{c}\text { Distance from } \\
\text { Obstacles (m) }\end{array}$ & $>200$ & $100-200$ & $50-100$ & $20-50$ & $<20$ \\
\hline $\begin{array}{c}\text { Traffic volume } \\
\text { (ship/day) }\end{array}$ & $0-10$ & $10-15$ & $15-25$ & $25-70$ & $>70$ \\
\hline Special operations (\%) & $0-10$ & $10-16$ & $16-30$ & $30-60$ & $>60$ \\
\hline $\begin{array}{c}\text { Transportation } \\
\text { services (\%) }\end{array}$ & $95-100$ & $95-90$ & $80-90$ & $70-80$ & $<70$ \\
\hline $\begin{array}{c}\text { Improvement rate of } \\
\text { navigation aids (\%) }\end{array}$ & $90-100$ & $80-90$ & $65-80$ & $50-65$ & $<50$ \\
\hline
\end{tabular}

\subsection{Determining the weight of risk factors}

The results of expert consultation collected are sorted out and the weights of factors at different levels are calculated respectively. Following is an example of the first level risk factors set. By calculating the first level of risk factors, the second level of risk factors can be obtained, as shown in Table 2.

Table 2. Comparison and judgment of the first level risk factors

\begin{tabular}{|c|c|c|c|c|}
\hline & $\begin{array}{c}\text { Hydrological } \\
\text { conditions }\end{array}$ & Channel & Traffic & Management \\
\hline $\begin{array}{c}\text { Hydrological } \\
\text { conditions }\end{array}$ & 1 & 0.922 & 0.983 & 2.793 \\
\hline Channel & 1.085 & 1 & 0.864 & 2.148 \\
\hline Traffic & 1.017 & 1.157 & 1 & 3.113 \\
\hline Management & 0.358 & 0.466 & 0.321 & 1 \\
\hline
\end{tabular}

From the Table 2, we can get the judgment matrix A.

$$
\mathbf{A}=\left(\begin{array}{cccc}
1 & 0.922 & 0.983 & 2.793 \\
1.085 & 1 & 0.864 & 2.148 \\
1.017 & 1.157 & 1 & 3.113 \\
0.358 & 0.466 & 0.321 & 1
\end{array}\right)
$$

Processing the above matrix, the weights of $\mathbf{u}_{1}, \mathbf{u}_{2}$ and $\mathbf{u}_{3}$ are obtained respectively. $\mathbf{W}=\left(\mathbf{W}_{1} \mathbf{W}_{2} \mathbf{W}_{3} \mathbf{W}_{4}\right)=$

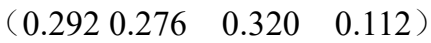

\section{Consistency check $C R=0.0052<0.90$}

Therefore, the consistency checks of the judgment matrix of the first level risk factors set can be judged, and the weights of the factors $\boldsymbol{u}_{1}, \boldsymbol{u}_{2}$ and $\boldsymbol{u}_{3}$ can be obtained, as shown in Table 3.

Table 3. Weight of the second level risk factors

\begin{tabular}{|c|c|c|}
\hline $\begin{array}{c}\text { The first level } \\
\text { factors }\end{array}$ & The second level factors & Weights \\
\hline \multirow{2}{*}{$\begin{array}{c}\text { Hydrological } \\
\text { conditions } \mathbf{u}_{1}\end{array}$} & Visibility $\left(u_{11}\right)$ & 0.333 \\
\cline { 2 - 3 } & Wind $\left(u_{12}\right)$ & 0.356 \\
\hline \multirow{3}{*}{ Channel $\mathbf{u}_{2}$} & Flow $\left(u_{13}\right)$ & 0.311 \\
\cline { 2 - 3 } & Width $\left(u_{21}\right)$ & 0.303 \\
\cline { 2 - 3 } & Curvature $\left(u_{22}\right)$ & 0.248 \\
\cline { 2 - 3 } & Crossing angle $\left(u_{23}\right)$ & 0.236 \\
\hline \multirow{2}{*}{ Traffic $\mathbf{u}_{3}$} & Obstacles $\left(u_{24}\right)$ & 0.213 \\
\cline { 2 - 3 } & Traffic volume $\left(u_{31}\right)$ & 0.599 \\
\hline \multirow{2}{*}{ Management $\mathbf{u}_{4}$} & Transportation services $\left(u_{41}\right)$ & 0.599 \\
\cline { 2 - 3 } & Navigation aids $\left(u_{42}\right)$ & 0.401 \\
\hline
\end{tabular}




\subsection{Recognition of calculation results}

Taking the navigation safety index system of LNG ships in a certain section of the lower reaches of the Yangtze River as an object of study, consulting relevant experts and professionals to determine the value of the evaluation index, the evaluation index affecting the navigation safety of LNG ships in this section can be obtained, as shown in Table 4.

Table 4. Measurement and estimation of navigation safety assessment indicators for LNG ships

\begin{tabular}{|c|c|c|}
\hline $\begin{array}{l}\text { Evaluation } \\
\quad \text { index }\end{array}$ & Definition & Value \\
\hline Visibility & \begin{tabular}{|l} 
Days of poor annual visibility \\
(days/years)
\end{tabular} & 29 \\
\hline Wind & Wind speed $(\mathrm{m} / \mathrm{s})$ & 14.8 \\
\hline Flow & Maximum velocity of flow $(\mathrm{m} / \mathrm{s})$ & 1.73 \\
\hline Width & $\begin{array}{l}\text { Average length of vessel allowed to } \\
\text { navigate/narrowest channel width (\%) }\end{array}$ & 1.21 \\
\hline Curvature & \begin{tabular}{|l}
$\begin{array}{l}\text { Maximum channel bending angle } \\
\text { (degree) }\end{array}$ \\
\end{tabular} & 29 \\
\hline Crossing & $\begin{array}{l}\text { Maximum crossing angle (degree) } \\
\text { between channel and sub channel }\end{array}$ & 50 \\
\hline Obstacles & $\begin{array}{l}\text { Distance }(\mathrm{m}) \text { from the nearest } \\
\text { obstruction to the channel }\end{array}$ & 180 \\
\hline $\begin{array}{l}\text { Traffic } \\
\text { Volume }\end{array}$ & $\begin{array}{l}\text { Average annual throughput (weighted } \\
\text { traffic volume) (number of } \\
\text { vessels/day) }\end{array}$ & 41.7 \\
\hline $\begin{array}{c}\text { Special } \\
\text { operations }\end{array}$ & $\begin{array}{l}\text { Annual vessel traffic volume/total } \\
\text { traffic volume (non-weighted) (\%) for } \\
\text { special operations }\end{array}$ & 8 \\
\hline $\begin{array}{c}\text { Transportation } \\
\text { services }\end{array}$ & $\begin{array}{l}\text { Including VTS, VHF, cruise boats and } \\
\text { other equipment rate }(\%)\end{array}$ & 75 \\
\hline $\begin{array}{l}\text { Navigation } \\
\text { aids }\end{array}$ & $\begin{array}{l}\text { Number of channels with perfect } \\
\text { navigation aid information/total } \\
\text { channel number }(\%)\end{array}$ & 85 \\
\hline
\end{tabular}

The detailed steps for the second-level fuzzy comprehensive evaluation of LNG ships in a certain section of the lower reaches of the Yangtze River are as follows:

$$
\begin{aligned}
& \mathbf{B}_{1}=\mathbf{W}_{1}^{(2)} \bullet \mathbf{R}_{1}=\left(w_{11}, w_{12}, w_{13}\right) \bullet\left(\begin{array}{lllll}
r_{11} & r_{12} & r_{13} & r_{14} & r_{15} \\
r_{21} & r_{22} & r_{23} & r_{24} & r_{25} \\
r_{31} & r_{32} & r_{33} & r_{34} & r_{35}
\end{array}\right) \\
& =\left(\begin{array}{lll}
0.317 & 0.428 & 0.255
\end{array}\right) \bullet\left(\begin{array}{ccccc}
0 & 0 & 0.567 & 0.433 & 0 \\
0 & 0 & 0.54 & 0.46 & 0 \\
0 & 0 & 0.97 & 0.03 & 0
\end{array}\right) \\
& =\left(\begin{array}{lllll}
0 & 0 & 0.6582 & 0.3418 & 0
\end{array}\right)
\end{aligned}
$$

Similarly, the evaluation vectors $\mathbf{B}_{2} 、 \mathbf{B}_{3} 、 \mathbf{B}_{4}$ can also be obtained for the channel condition.

$$
\begin{aligned}
& \mathbf{B}_{2}=\left(\begin{array}{lllll}
0 & 0 & 0.1677 & 0.5946 & 0.2376
\end{array}\right) \\
& \mathbf{B}_{3}=\left(\begin{array}{lllll}
0.1013 & 0.2057 & 0 & 0.6078 & 0.0852
\end{array}\right) \\
& \mathbf{B}_{4}=\left(\begin{array}{lllll}
0 & 0 & 0.2868 & 0.7132 & 0
\end{array}\right)
\end{aligned}
$$

Therefore, the final evaluation $\mathbf{B}$ of navigation environment safety can be obtained by the results of the second level evaluation.

$$
\begin{aligned}
& \mathbf{B}=\mathbf{W} \bullet \mathbf{R}=\left(\begin{array}{llll}
w_{1} & w_{2} & w_{3} & w_{4}
\end{array}\right) \bullet\left(\begin{array}{l}
\mathbf{B}_{1} \\
\mathbf{B}_{2} \\
\mathbf{B}_{3} \\
\mathbf{B}_{4}
\end{array}\right) \\
& =\left(\begin{array}{lllll}
0.0324 & 0.0658 & 0.2706 & 0.5383 & 0.0928
\end{array}\right)
\end{aligned}
$$

\subsection{Anti-fuzzy of final evaluation vector}

$$
\begin{aligned}
& M=\frac{\sum_{i}^{n} b\left(u_{i}\right) * u_{i}}{\sum_{i}^{n} b\left(u_{i}\right)} \\
& =\left(\begin{array}{llll}
0.0324 & 0.0658 & 0.2706 & 0.5383
\end{array}\right. \\
& 0.0928) \bullet\left(\begin{array}{lllll}
-2 & -1 & 0 & 1 & 2
\end{array}\right)^{\mathrm{T}} /(0.0324 \\
& +0.0658+0.2706+0.5383+0.0928) \\
& =0.5933
\end{aligned}
$$

According to the preceding contents, we can know that the membership degree of the first level risk factors is the evaluation vector calculated for the second level risk factors. Based on this, we can get the navigation safety risk status of inland LNG ships. According to the results of anti-fuzzy, it can be concluded that the current inland LNG shipping safety risk situation is between "general" and "higher".

\section{Safety guarantee measures of LNG inland river transportation based on risk management}

\subsection{Legal safeguard}

Firstly, we should speed up the formulation of LNG shipping and operation regulations by referring to the relevant LPG specifications. Secondly, we should speed up the research and formulation of LNG inland river standard ship form, and strive to include it in the National Outline for the Development of Inland River Standardized Ship Form. 


\subsection{Personnel safeguard}

Workers involved in LNG loading and unloading operations should be trained in LNG professional knowledge. They should be qualified by the competent transport authorities (crew members are qualified by the maritime administration), and only after obtaining the qualification certificate, can they work on the job. Operating units must organize employees to learn laws and regulations and raise their legal awareness. At the same time, enterprises should organize practitioners to learn according to the specific conditions of their departments, so that they can master the knowledge of LNG risks and emergency measures when accidents occur, and specific requirements of safe handling, so as to improve the professional quality of practitioners.

\subsection{Ships safeguard}

According to the "IGC Rules" and specifications, the structure, equipment, accessories, devices and materials of LNG carriers shall be subject to initial inspection, periodic inspection, interim inspection, annual inspection and additional inspection. At the same time, it is necessary to establish LNG ship fault database as soon as possible. Ship Inspection Departments and Maritime Departments should strengthen LNG Ship Inspection. Shipping companies should scientifically manage LNG ships under their jurisdiction. The crew on board should have a good grasp of the safety situation of the equipment on board and the maintenance work. Especially they should focus on the inspection and maintenance of the equipment.

\subsection{Security management}

In view of the unsafe factors existing in port $\mathrm{LNG}$ operation, it is necessary to speed up the training of professional personnel of maritime authorities, formulate safety measures for LNG ships entering and leaving the port, strengthen ship safety inspection, and promote port and shipping enterprises to establish a standardized system of safety and quality. At the same time, the owners, operators or managers of LNG ships and the personnel on board should attach importance to the safety management of LNG ships and strictly implement ISM rules. It is necessary to draw up corresponding safety operation rules according to the regulations of LNG ship management in western countries and the safety operation guidelines provided by equipment manufacturers. Establishing a scientific, systematic and procedural safety management system to ensure the institutionalization and standardization of maintenance, maintenance and troubleshooting.

\subsection{Emergency plans}

In accordance with the requirements of the guidelines for the preparation of emergency plans for production security accidents in production and operation units, corresponding emergency rescue plans are formulated to form an emergency plan system, which is connected with the emergency plans of local people's governments and relevant departments. Emergency plan can be divided into three levels: general plan, special plan and on-site disposal plan. The general plan expounds the emergency policy, emergency organization structure and corresponding responsibilities of the plan as a whole, as well as the general idea of emergency action. Special plans are aimed at specific and specific types of emergencies, such as emergency plans for flood control and prevention, emergency plans for environmental emergencies, etc. The on-site plan is based on the special plan and is compiled according to the specific situation of the site. It is a plan for a specific site (i.e. the site is the target), usually for a place, device or important protective area where the accident risk is high.

Examples of on-site plans to be developed are as follows:

Emergency disposal plan for ship leakage, fire and explosion. Emergency Plan for Major Safety Accidents of Special Equipment. Emergency Disposal Plan for Personnel Asphyxia Accident.

\subsection{Exercise of emergency plans}

According to the actual situation, regular drills of accident emergency plan will be held. Through the drill, we can find the defect of the plan procedure, improve the coordination among the emergency departments, agencies and personnel, enhance the public's confidence and emergency awareness in dealing with emergency rescue, improve the proficiency and technical level of emergency 
personnel, further clarify their positions and responsibilities, and improve the coordination among departments. Improving the overall emergency response capability.

\section{Conclusion}

By analyzing and evaluating the risk of LNG transportation, the risk assessment index of LNG accident is established, and the safety safeguard measures of LNG inland waterway transportation are put forwarded. The main conclusions are as follows.

The factors affecting the navigation environment of inland LNG vessels can be divided into four aspects: natural environment factors, channel factors, traffic factors and management factors. These factors are interrelated, interactional, complex and changeable. Only by accurately grasping the changing law of each factor, accurately locating in time and drawing up the correct route can the navigation system be guaranteed.

Accidents such as collision, collision, damage, wave damage, grounding, fire, explosion and sinking may occur during inland navigation of small LNG vessels. Relatively speaking, LNG leakage accident, fire and explosion accident and ship damage accident are the main dangers of LNG inland navigation. The main causes of the above-mentioned accidents are unsafe human behavior, quality defects or faults of equipment and facilities, other external adverse factors, improper operation or mismatch of ships, and poor hydrological and meteorological conditions.

Indicators affecting navigation safety risk assessment of inland LNG vessels are wind, visibility, flow, channel width, channel curvature, channel intersection angle, obstacles, traffic flow, special operations, traffic management and navigation information perfection. Applying the analytic hierarchy process to determine the evaluation index system, the risk assessment index of LNG transport accident is established. Taking a certain section of the lower reaches of the Yangtze River as an example, the navigation safety risk situation of inland LNG ships is evaluated and analyzed.

Risk identification, risk assessment and ship operation simulation experiments are the main technical means of LNG ship safety management. Based on risk identification and risk assessment of LNG ship transportation, here puts forward safety assurance measures of LNG ship transportation based on risk management from aspects of personnel, ships, safety management, laws and regulations, and emergency plans.

\section{References}

1. H. L. Gan, WHUT (2012)

2. Y. Q. Wen, L. Wang, X. Yang, C. S. Xiao, C. H. Zhou, CSSJ, 24, 5 (2014)

3. C. M. Wang, WHUT (2011)

4. W. Z, Gou, WHUT (2011)

5. H. G. Wu, C. J. Liu, Y. J. Xiao, Journal of Shanghai Maritime University, 33, 2 (2012)

6. X. D. Zhang, H. Zhang, W. J. Chen, Y. J. Xiao. Journal of Shanghai Maritime University, 35, 1 (2012)

7. H. L. Li, C. B. Yang, Port \& Waterway Engineering, 6, 85-88+113 (2013)

8. H. R. Wang, X. Q. Ma, CSSJ, 3, 131-135+177, (2007)

9. Q. F. Wang, X. Y. Cui, Journal of Jiangsu University of Science and Technology (Natural Science Edition), 33, 1 (2019)

10. X. Dou, W. Q. Wu, M. Song, Navigation of China, 40, 2 (2017)

11. K. Wang, Y. R. He, Z. Y. Liu, X. M. Qian, J. Hazard. Mater, 366 (2018)

12. W. Molen, H. Ligteringen, J. C. Lem, et al. J. Waterw. Port Coast. Ocean Eng, 129, 1 (2003)

13. M. Hightower, L. Gritzo, A. Luketa-Hanlin, Process. Saf. Prog. 24, 3 (2005)

14. D. W. Johnson, J. B. Cornwell, J. Hazard. Mater.140, 3 (2007)

15. D. W. Hissong, J. Hazard. Mater. 140, 3 (2007)

16. H. Kim, J. S. Koh, Y. Kim, THEOFANOUS T G, Korean J. Chem. Eng. 22, 1 (2005)

17. T. Elsayed, Appl. Ocean Res. 31, 3 (2009)

18. R. Bubbico, S. D. Cave, B. Mazzarotta, J. Loss Prev. Process Ind. 22, 5 (2009)

19. T. C. Nwaoha, Z. Yang, J. Wang, et al, Ocean Eng. 72, 11 (2013)

20. M. S. Kim, S. B. Kwon, S. K. Kim, Constr. Steel. Res. 156 (2019) 